\title{
Optimal parameters for drilling explosions when developing coal deposits by open-pit method
}

\author{
Pavel Afanasev ${ }^{1, *}$, Andrey Pasynkov ${ }^{1}$, Ivan Kurta ${ }^{2}$ \\ ${ }^{1}$ Saint-Petersburg Mining University, 2, 21 Line V.O., 199002, St. Petersburg, Russia \\ ${ }^{2}$ Ukhta State Technical University, 13, Pervomayskaya St., 169300, Ukhta, Republic of Komi, Russia
}

\begin{abstract}
The article discusses two deposits of coal mining by the open method. The «Zarechnyi» open-pit is located in Kuzbass, and the «Vostochno-Beiskyi» open-pit is in Khakassia. The main parameters of drilling and blasting operations are given, the geological structure of the deposits is described. The methods of calculating the specific charge, the diameter of the wells and the grid of wells are considered. Blasting operations are an integral part of the mining process. The cost of finished products and the quality of raw materials supplied to the crushing and screening complexes depend on the results of blasting of the rock mass. The currently used retractable blasting technologies, produced according to standard designs, lead to large energy losses during the explosion, as well as to the output of the oversized fraction, which in turn leads to downtime, reduced productivity and breakdown of transport and loading equipment. The paper substantiates the parameters of drilling and blasting operations taking into account the physical processes occurring in the explosive cavity and during the stress wave propagation in the rock mass. Parameters of detonation products are estimated on the basis of shock-wave compression, the refraction of a detonation wave into a rock based on the theory of the breakdown of an arbitrary discontinuity, the stress wave propagation taking into account polymorphic transformations and dissipation energy. Recommendations for reducing the specific charge of explosives, for choosing the diameter of the borehole charge and the grid of wells are proposed.
\end{abstract}

\section{Introduction}

The paper presents the analysis of drilling and blasting parameters for coal open-pits of Kuzbass and Khakassia on the example of the open-pits "Zarechnyi» and "VostochnoBeiskyi». The open-pit «Zarechnyi» is located on the territory of Prokopyevskyi district of the Kemerovo region in the Central part of the Erunakovskyi geological-industrial region of Kuzbass. The project provides for a two-flank opening, which will be carried out through the southern and northern entrance trench. Two-flank opening allows mining of seams from both sides, which reduces the distance of transportation of overburden and coal. On the

\footnotetext{
${ }^{*}$ Corresponding author: afan@mail.ru
} 
open-pit «Zarechnyi» the combined system of development - transportless and transport is applied.

As a technological scheme of overburden operations, a longwall scheme of mining out with the use of excavator-automobile complexes is used. Since in the geological structure there is an inter-area with a capacity of up to $6 \mathrm{~m}$, the stripping work is carried out by excavators, which are coal mining. The height of the overburden benches is from 10 to 15 $\mathrm{m}$. In close proximity to coal seams there can be also overburden, so such bare grounds are mined out layer by layer. The minimum width of the working platform during mining operations on the bench shall be in line the excavator parameters at least $18 \mathrm{~m}$. The slope angle of the loading face is $70^{\circ}$, unloading face $-55^{\circ}$.

«Vostochno-Beiskyi» open-pit is developing a strip mining of CHALPAN bare grounds (geological bare grounds Chalpan-1 and Chalpan-2) of the eastern part of the Beisk coal deposit, located on the territory of the municipality in the Beisk district of the Republic of Khakassia, $10 \mathrm{~km}$ North-East of the village of Kirba. The area of the Beiskyi deposit is covered by a powerful layer of flood alluvial sand and gravel sediments from 0 to $40 \mathrm{~m}$, with the exception of the Eastern part of the deposit. The strata of overburden rocks are represented by interbedding of siltstones, sandstones, mudstones and coals. The individual difference between rocks is in the strata of overburden following amounts: siltstone is 60,4 $\%$, sandstones $-29,0 \%$ mudstone- $5,6 \%$ aleurolite carbonaceous- $2,1 \%$, argellite carbonaceous $-1,3 \%$, gravelite $-1,1 \%$, conglomerates $-0,5 \%$.

The opening was carried out by the Western entrance trench of the external laying and the split trench of the Western block. The open-pit used a combined system of development - transportless and transport. The height of the benches on the outer overburden and thick inter-area is from 20 to $30 \mathrm{~m}$, on low-capacity inter-areas - from 5 to $10 \mathrm{~m}$.

The necessary rock crushing is provided by the choice of the correct method of blasting in these conditions. There are various works that determine the parameters of drilling and blasting operations [1-4], but this article discusses the methods used in the design of the Russian practice.

The most fully the reduction range is characterized by the granulometric composition of the exploded rock mass, the definition of which in practice is very laborious. At mining companies, to assess the quality of the explosion, the output of oversized pieces is determined at $1 \mathrm{~m}^{3}$ of the exploded rock mass. The output of oversized fractions affects on:

1. Reliability and the performance of loading and transport equipment;

2. Costs and time spent on secondary crushing and also the derangement of company.

The size of the maximum permissible pieces of blown up rock in the collapse is limited by the parameters of the movable objects of the excavation and loading, transport and crushing equipment. This article discusses the overburden, so let's stop at the maximum permissible piece for the excavation and loading equipment $[5,6]$.

The maximum size of a piece that can be in the collapse of the rock mass after a mass explosion is determined by the criterion:

$$
d \leq 0,75 \sqrt[3]{V_{s h}}
$$

where $V_{s h}$ - shovel volume.

According to the work [5] the maximum permissible sizes of pieces of blasted rock mass taking into account the different volume of shovels are given in table 1 . 
Table 1. The dependence of the maximum permissible size of the piece of the shovel volume.

\begin{tabular}{|c|c|c|c|c|c|c|c|}
\hline $\boldsymbol{V}_{\boldsymbol{s} \boldsymbol{h}, \mathbf{M}^{\mathbf{3}}}$ & $\mathbf{1}$ & $\mathbf{2}$ & $\mathbf{3}$ & $\mathbf{4}$ & $\mathbf{6}$ & $\mathbf{8}$ & $\mathbf{1 0 - 2 0}$ \\
\hline The maximum permissible size of the piece, $\mathrm{m}$ & 0.75 & 0.9 & 1.0 & 1.1 & 1.3 & 1.5 & 1.6 \\
\hline
\end{tabular}

Thus, for excavators used in the open-pits «straight» and «reverse» shovel PC 3000, PC 2000-the maximum size of the piece should not exceed 1,6 m, and for PC 1250, ECG-8i, R 984C-1,5 m.

The diameter of the blast holes is determined by the data from the «Reference-book on standards of drilling and blasting operations»:

$$
d_{b r}=9 \cdot H+35,5 \cdot K_{p}+33,5 \cdot F-195
$$

where $\mathrm{H}=10 \mathrm{~m}, 15 \mathrm{~m}, 20 \mathrm{~m}$-the height of the blast out bench;

$\mathrm{K}_{\mathrm{p}}=1,3$ - fragmentation index of the blasted rock mass;

$\mathrm{F}=6$-group of soils due to "Construction code and regulations" (siltstones and sandstones).

Versions of the diameters of the blast wells are presented in table 2.

Table 2. The dependence of the blast well diameters of the bench height and groups soils according to "Construction code and regulations".

\begin{tabular}{|c|c|}
\hline \multirow{2}{*}{ The height of the bench, $\mathbf{m}$} & $\begin{array}{c}\text { A group of soils according to "Construction code and } \\
\text { regulations" }\end{array}$ \\
\cline { 2 - 3 } & $\mathbf{6}$ \\
\hline 10 & $d_{b r}=140 \mathrm{~mm}$ \\
\hline 15 & $d_{b r}=190 \mathrm{~mm}$ \\
\hline 20 & $d_{b r}=230 \mathrm{~mm}$ \\
\hline
\end{tabular}

On the open-pits taken two sizes of jackbit: $200 \mathrm{~mm}$ (open-pit «Zarechnyi») and 216 $\mathrm{mm}$ («Vostochno-Beiskyi» open-pit). As a comment, it should be noted that, as a rule, on the open-pit «Zarechnyi» form the benches with a height of $10 \mathrm{~m}$, and on the «VostochnoBeiskyi» open-pit - $15 \mathrm{~m}$.

Specific charge of explosives is determined by the formulas:

$$
\text { a) } q=\frac{q_{A} \cdot e_{B B} \cdot k_{d} \cdot \gamma}{2,6}
$$

where $q_{A^{-}}$is the reference outgo of grammonite $79 / 21$ with certified size pieces $500 \mathrm{~mm}$, $\mathrm{kg} / \mathrm{m}^{3} ; k_{d}$ - is the correction coefficient for the permissible size of a piece of the destroyed rock mass, $\gamma$ - is the rock density, $\mathrm{kg} / \mathrm{m}^{3} ; e_{B B}$ - performance quotient of explosives.

$$
\text { b) } q=q_{A} k_{B B} k_{H} k_{D} k_{C} k_{Z} k_{P}\left(1 \pm K_{B A P}\right)
$$

where $q_{A}$-the reference specific charge; $k_{H}$ - coefficient, taking into account the size of the oversized piece; $k_{B B}$ - conversion coefficient from gramonite $79 / 21$ to a used explosives; $k_{D}$ - coefficient, taking into account the intensity of crushing; $k_{C}$ - coefficient, taking into account the sequence of ignition; $k_{Z}$ - coefficient, taking into account the conditions of explosion; $k_{P}$ - coefficient, charge density; $K_{B A P}$ - coefficient of variation. 
Analysis of the formulas used in the design shows:

1. The choice of reference charge of explosives is based on the height of the bench and the group of soils determined by "Construction code and regulations", although the value of the reference charge is obtained on the rock samples.

2. In accordance with "Construction code and regulations" soils are divided into groups on the difficulty of development by single-shovel excavators. There is no indication that the group of soils taken for calculations should refer to the original rock mass or to the exploded rock mass.

3. Physical and mechanical properties of rock that affect the stress wave transmission in the rock mass, as well as are criteria for the destruction of the rock mass, etc., are not taken into account.

4. For a concentrated charge, the reference specific charge is obtained, although blasthole charges are used, and the nature of the destruction of the rock mass is aimed at obtaining an explosion funnel with the maximum possible destructible volume of the rock. When the benched breaking, at least two free surfaces are formed, which leads to a change in the volume of the blasted rock mass towards an increase in comparison with the concentrated charge.

When calculated according to the formula (3), the specific charge of explosives when using granulite PS-2 is $0.32 \mathrm{~kg} / \mathrm{m}^{3}$ for category II of rock jointing, and $0.49 \mathrm{~kg} / \mathrm{m}^{3}$ for category III of rock jointing, in the case of using emulsolite A-20 for category II- 0.22 $\mathrm{kg} / \mathrm{m}^{3}$, for category III $-0.34 \mathrm{~kg} / \mathrm{m}^{3}$. When calculating by formula (4), we obtain that when using granulite PS-2, depending on the height of the bench, we obtain: $10 \mathrm{~m}$-from 0.23 to $0.23 \mathrm{~kg} / \mathrm{m}^{3} ; 20 \mathrm{~m}$-from 0.28 to $0.22 \mathrm{~kg} / \mathrm{m}^{3} ; 30 \mathrm{~m}$-from 0.27 to $0.21 \mathrm{~kg} / \mathrm{m}^{3}$; in the case of using emulsolite A-20 $10 \mathrm{~m}$-from 0.27 to $0.21 \mathrm{~kg} / \mathrm{m}^{3} ; 20 \mathrm{~m}$-from 0.26 to $0.20 \mathrm{~kg} / \mathrm{m}^{3} ; 30 \mathrm{~m}$ from 0.25 to $0.19 \mathrm{~kg} / \mathrm{m}^{3}$.

In fact, the specific charges are $0,64-0,7 \mathrm{~kg} / \mathrm{m}^{3}$ for the conditions of the open-pit «Zarechnyi» and for the conditions of the «Vostochno-Beiskyi» open-pit $0,6-0,75 \mathrm{~kg} / \mathrm{m}^{3}$.

The line of least resistance is determined by the formula (5), which is used in the documentation for the mining development, the calculated values are presented in table 3 :

$$
W=0,9 \sqrt{\frac{p}{q}}
$$

where $p$ - capacity of one running meter of the well, $\mathrm{kg} / \mathrm{m} ; q$ - specific charge of explosives, $\mathrm{kg} / \mathrm{m}^{3}$.

Table 3. The grid of wells and the line of least resistance estimated and actual.

\begin{tabular}{|c|c|c|}
\hline & $\begin{array}{c}\text { The estimated grid of } \\
\text { wells }\end{array}$ & The actual grid of wells \\
\hline Open-pit «Zarechnyi» & $7.2 \times 7.6 ; 7.1 \times 7.8$ & $6 \times 6 ; 6 \times 5$ \\
\hline «Vostochno-Beiskyi» open-pit & $7 \times 7 ; 6 \times 6$ & $5 \times 7$ \\
\hline
\end{tabular}

Most of the formulas used in the calculation of the drilling and blasting operation parameters do not take into account the detonation characteristics of the explosive, such as the detonation velocity, the pressure of the detonation products, the mass velocity of the detonation products particles, do not estimate the crusher zone during the stress wave propagation, and also the physical processes occurring during loading of rock.

\section{Materials and Methods}


To solve the problem of rock mass destruction, it is necessary to take into account the processes occurring in the explosive cavity, and also to calculate the parameters of stress waves to determine the crusher zones [7-11].

Justification of the method is given in various works. In this paper we will focus on the key positions. The explosive charge density is an important characteristic for determining the mechanism of detonation decomposition. Convection mechanism of chemical decomposition of the reaction proceeding on the principle of «hot» points is basic when charge density is less than $800 \mathrm{~kg} / \mathrm{m}^{3}$, at higher densities the prevailing mechanism is shock-wave [12]. Therefore, the pressure at the front of the detonation wave is determined by the formula:

$$
P_{\partial}=\left(1-\alpha_{\kappa o v} \rho_{B B}\right) \frac{\rho_{B B} D^{2}}{(\gamma+1)}
$$

where $\gamma$ - the polytropic coefficient, $\rho_{B B}$ - explosives density, $\alpha_{\kappa o v}$-incompressible volume.

Then the calculation of the shock wave parameters on the explosive cavity wall by the breakdown of an arbitrary discontinuity is made. In the future, the initial value problem of stress wave propagation in a rock mass with boundary conditions obtained on the explosive cavity wall is solved. The polymorphic transformations at the wave front are taken into account when the wave propagates $[12,13]$ and energy dissipation is calculated. Energy dissipation is understood to mean an energy that remains in a rock mass during the stress wave passage. The dissipated energy is not involved in the further formation of mechanical disturbances, which leads to a decrease in the parameters of stress waves [14,15].

Polymorphic transitions are taken into account on the basis of comparison of formulas for durability in the kinetic theory of resisting power and in the thermokinetic theory of aggregative transitions and the dependence of the volume wave velocity determination for static unloading adiabat in the presence of newly created medium defects is proposed (7):

$$
C_{V}=\sqrt{\frac{1+v}{3(1-v)}} \frac{B}{\left(\alpha_{c r}\right)^{n}}
$$

where $B, n$-semi-empirical coefficients; $\alpha_{c r}$ - a value that has a physical meaning as a measure of rock jointing; $v$ - Poisson's ratio.

The cylindrical charge was divided into three parts: the upper and lower parts (front) and the central part. The parameters of the stress waves in the front parts was determined using method I. Hawk, and in the central part as an elongated cylindrical charge. The criteria of the ruptured zones were the dynamic strength limits of the rock mass. The transition from the sample properties to the rock mass properties is based on the Protodyakonov and Korshunov method, and to the dynamic strength limits by work [12, $14]$.

\section{Discussion and Results}

The calculations were carried out and the ruptured zones were obtained, the parameters of the well grid and the length of the stemming were proposed and the specific charge was calculated (tables 4, 5).

Table 4. The calculated parameters of the drilling and blasting operations for Emulsolite A-20 for the conditions of the «Vostochno-Beiskyi» open-pit. 


\begin{tabular}{|l|c|c|}
\hline \multicolumn{1}{|c|}{ The parameter } & Sandstone & Aleurolite \\
\hline The diameter of the borehole. $\mathrm{mm}$ & 215 & 215 \\
\hline $\begin{array}{l}\text { The radius of the crack formation zone of a cylindrical charge }\left(\mathrm{R}_{\mathrm{cr}}\right) . \\
\mathrm{m}\end{array}$ & 4.4 & 4.2 \\
\hline The radius of the crack formation zone of a spherical charge. $\mathrm{m}$ & 1.3 & 0.9 \\
\hline The estimated line of least resistance Wp. $\mathrm{m}$ & 8.8 & 8.4 \\
\hline The actual line of least resistance Wp. $\mathrm{M}$ & 8.0 & 8.0 \\
\hline The length of stemming $l_{s t .} \mathrm{M}$ & 3.4 & 3.3 \\
\hline The length of charge $l_{c h}$ when the height of the benches is $8 \mathrm{~m} . \mathrm{m}$ & 6.2 & 6.8 \\
\hline The length of charge $l_{c h}$ when the height of the benches is $12 \mathrm{~m} . \mathrm{m}$ & 10.2 & 10.8 \\
\hline The length of charge $l_{c h}$ when the height of the benches is $15 \mathrm{~m} . \mathrm{m}$ & 13.2 & 13.8 \\
\hline $\begin{array}{l}\text { The calculated specific charge when the height of the benches is } 8 \\
\mathrm{~m} . \mathrm{kg} / \mathrm{m}^{3}\end{array}$ & 0.37 & 0.41 \\
\hline $\begin{array}{l}\text { The calculated specific charge when the height of the benches is } 12 \\
\mathrm{~m} . \mathrm{kg} / \mathrm{m}^{3}\end{array}$ & 0.33 & 0.35 \\
\hline $\begin{array}{l}\text { The calculated specific charge when the height of the benches is } 15 \\
\mathrm{~m} . \mathrm{kg} / \mathrm{m}^{3}\end{array}$ & 0.35 & 0.36 \\
\hline
\end{tabular}

Table 5. The calculated parameters of the drilling and blasting operations for Emulsolite A-20 for the conditions of the open-pit «Zarechnyi».

\begin{tabular}{|l|c|c|}
\hline \multicolumn{1}{|c|}{ The parameter } & Sandstone & Aleurolite \\
\hline The diameter of the borehole. $\mathrm{mm}$ & 215 & 215 \\
\hline $\begin{array}{l}\text { The radius of the crack formation zone of a cylindrical } \\
\text { charge ( } \mathrm{R}_{\mathrm{cr}} \text { ). } \mathrm{m}\end{array}$ & 4.8 & 4.3 \\
\hline $\begin{array}{l}\text { The radius of the crack formation zone of a spherical charge. } \\
\mathrm{m}\end{array}$ & 1.46 & 1.05 \\
\hline The estimated line of least resistance Wp. $\mathrm{m}$ & 8.5 & 8.5 \\
\hline The actual line of least resistance Wp. $\mathrm{m}$ & 8 & 8.0 \\
\hline The length of stemming $l_{s t . \mathrm{M}}$ & 3.6 & 3.4 \\
\hline $\begin{array}{l}\text { The length of charge } l_{c h} \text { when the height of the benches is } 8 \\
\text { m. } \mathrm{m}\end{array}$ & 4.4 & 4.6 \\
\hline $\begin{array}{l}\text { The length of charge } l_{c h} \text { when the height of the benches is } 12 \\
\mathrm{~m} . \mathrm{m}\end{array}$ & 8.4 & 8.6 \\
\hline $\begin{array}{l}\text { The length of charge } l_{c h} \text { when the height of the benches is } 15 \\
\text { m. } \mathrm{m}\end{array}$ & 11.4 & 11.6 \\
\hline $\begin{array}{l}\text { The calculated specific charge when the height of the } \\
\text { benches is } 8 \mathrm{~m} . \mathrm{kg} / \mathrm{m}^{3}\end{array}$ & 0.35 & 0.39 \\
\hline $\begin{array}{l}\text { The calculated specific charge when the height of the } \\
\text { benches is } 12 \mathrm{~m} . \mathrm{kg} / \mathrm{m}^{3}\end{array}$ & 0.31 & 0.33 \\
\hline $\begin{array}{l}\text { The calculated specific charge when the height of the } \\
\text { benches is } 15 \mathrm{~m} . \mathrm{kg} / \mathrm{m}^{3}\end{array}$ & 0.33 & 0.34 \\
\hline
\end{tabular}

As a result of calculations for the ruptured zones assessment, the parameters of the well grid are obtained, which are based on the physical processes occurring in the explosive cavity and in the rock mass. When using emulsion explosives, the specific charge of explosives is reduced due to large ruptured zones, but it should be noted that it is necessary to use wells of a smaller diameter ( $5-10 \%$ less) than those which calculated according to the existing method (1), since this it will reduce the size of the less effective (in terms of 
destruction) front parts of the well charge with a slight decrease in the well charge grid. The calculated specific charge of explosives according to this method coincides with the range of the actual specific charge of explosives in companies.

\section{Conclusion}

In spite of the fact that at the companies, with the help of practice, the necessary grid of wells is reached and the actual charge of explosives is specified, it occurs by the principle: rock - «black box». This method allows you to find additional options for adjusting the parameters of drilling and blasting operations, which improves the economic performance of production.

\section{References}

1. H. Abbaspour, C. Drebenstedt, M. Badroddin, A. Maghaminik, International Journal of Mining Science and Technology 28(6), 839-848 (2018)

2. M.I. Attalla, S.J. Day, T. Lange, W. Lilley, S. Morgan, Atmospheric Environment 42(34), 7874-7883 (2008)

3. S. Gerassis, M.T.D. Albuquerque, J.F. García, C. Boente, E. Giráldez, J. Taboada, J.E. Martín, Reliability Engineering and System Safety 188, 195-204 (2019)

4. T.B. Afeni, Mining Science and Technology 19(6), 736-739 (2009)

5. Dingxiang Zou, Metallurgical Industry Press and Springer Science+Business Media 699 (2017)

6. J.K. Furtney, E. Sellers, I. Onederra, Simple models for the complex process of rock blasting (Rock Fragmentation by Blasting Taylor \& Francis Group, London, 2013)

7. A.E. Frantov, A.E. Didyura, 9th international conference on physical problems of rock destruction, The Metallurgical Industry Press, $411-414$ (2017)

8. A. Mortazavi, M. Sharafisafa, A study of the effect of rock bridges on blast-induced wave propagation in jointed media (Rock Fragmentation by Blasting Taylor \& Francis Group, London, 2013)

9. Ya.I. Rudaev, D.A.Kitaeva, M.A. Mamadalieva, Zapiski Gornogo institute 222, 816$822(2016)$

10. L.F. Trivino, B. Mohanty, Proceedings of the 10th International Symposium on Rock Fragmentation by Blasting, 685-695 (2013)

11. S.P. Singh, H. Abdul, Proceedings of the 10th International Symposium on Rock Fragmentation by Blasting, 181-186 (2013)

12. G.I. Korshunov, M.L. Rudakov, P.I. Afanasyev, International Journal of Applied Engineering Research 11(9), 6168-6173 (2016)

13. P.I. Afanasev, K. Sergey, I. Valentin, International Journal of Mechanical Engineering and Technology 9(13), 865-868 (2018)

14. M.G. Menzhulin, A.Y. Khoreva, P.I. Afanasiev, S.A. Tyulkin, Gornyi Zhurnal 1, 42-46 (2017)

15. J.A. Sanchidrián, P. Segarra, L.M. López, Energy efficiency in rock blasting, 87-118 (2018) 